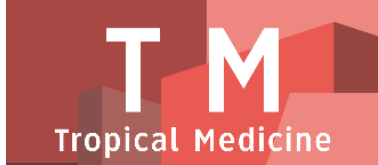

PAPER - OPEN ACCESS

Desain Senyawa Turunan Kuersetin sebagai Inhibitor Pertumbuhan Candida Albicans Menggunakan Analisis QSAR
Author
: Esti Mumpuni
DOI
: 10.32734/tm.v1i3.262
Electronic ISSN
: 2623-0542
Print ISSN
: 2623-0550

Volume 1 Issue 3 - 2018 TALENTA Conference Series: Tropical Medicine (TM)

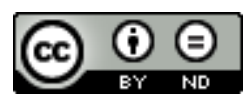

This work is licensed under a Creative Commons Attribution-NoDerivatives 4.0 International License.

Published under licence by TALENTA Publisher, Universitas Sumatera Utara
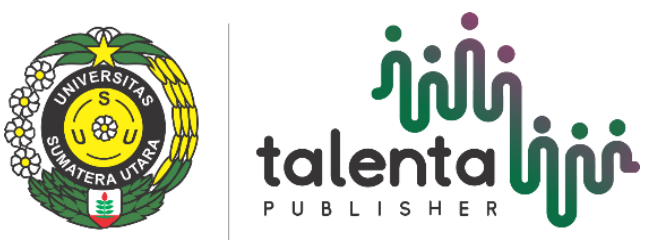


\title{
Desain Senyawa Turunan Kuersetin sebagai Inhibitor Pertumbuhan Candida Albicans Menggunakan Analisis QSAR
}

\author{
Esti Mumpuni $^{a^{*}}$, Agus Purwanggana ${ }^{\mathrm{b}}$, Esti Mulatsaric $^{\mathrm{c}}$, Yafi Lakstian $^{\mathrm{d}}$ \\ ${ }^{a b c d}$ Fakultas Farmasi, Universitas Pancasila, Jakarta Selatan, Indonesia \\ esti_mumpuni@yahoo.com
}

\begin{abstract}
Abstrak
Candida albicans adalah sejenis jamur oportunistik yang patogen bagi manusia dan terlibat dalam proses Oral Candidiasis (OC). Candida albicans merupakan spesies yang paling umum diisolasi dalam kasus klinis infeksi jamur invasif. Candida albicans hidup secara komensal di usus, faringeal oral, saluran kemih dan kulit. Senyawa alam seperti flavonoid, telah banyak dikembangkan untuk menghambat pertumbuhan Candida albicans salah satu diantaranya adalah kuersetin yang memiliki nilai MIC $197 \mu \mathrm{g} / \mathrm{mL}$ dalam menghambat pertumbuhan Candida albicans. Upaya peningkatan daya penghambatan kuersetin dalam proses inhibisi pertumbuhan Candida albicans dapat dilakukan dengan memodifikasi struktur kimia senyawa kuersetin secara komputasi. Penentuan MIC senyawa inhibitor candida albicans dari turunan kuersetin secara komputasi dilakukan menggunakan analisis QSAR dengan penentuan deskriptor menggunakan hyperchem dengan metode semi empiric Austin Model 1 dan analisis regresi multilinier (MLR) untuk menentukan model persamaan QSAR. Dari 24 persamaan QSAR yang dihasilkan, ditentukan persamaan QSAR terbaik untuk menentukan nilai MIC prediksi senyawa turunan kuersetin, yaitu : MIC $=970.428+(0.025$ Energi Ikat $)+$ $(110.503$ Energi HOMO) + (-100.354 Energi LUMO) + (-37.142 log P).Dari 91 senyawa turunan kuersetin yang diuji, diperoleh 74 senyawa yang memiliki nilai MIC lebih kecil dari kuersetin dan senyawa 2,6-diisopropil kuersetin merupakan senyawa dengan MIC terkecil yaitu $27.28 \mu \mathrm{g} / \mathrm{mL}$. Modifikasi struktur kimia senyawa kuersetin dapat meningkatkan aktivitas kuersetin sebagai inhibitor pertumbuhan candida albicans.
\end{abstract}

Kata Kunci: kuersetin, inhibitor, candida albicans, QSAR

\begin{abstract}
Candida albicans is a kind of opportunistic fungus that is pathogenic to humans and it's involved in the process of Oral Candidiasis (OC). Candida albicans live commensally in the intestine, oral pharyngeal, urinary tract and skin. Natural compounds such as flavonoids, have been widely developed to inhibit the growth of Candida albicans, one of them is quercetin which has a Minimum Inhibitory Concentration (MIC) value of $197 \mu \mathrm{g} / \mathrm{mL}$ in inhibiting the growth of Candida albicans. Study to increase the inhibitory activity of quercetin in the process of growth inhibition of Candida albicans can be done by modifying the chemical structure of quercetin computationally. The determination of MIC of candida albicans inhibitor compounds from quercetin derivative compounds was done using QSAR analysis with descriptor determination using hyperchem with semiempiric Austin Model 1 method and multilinier regression analysis (MLR) to determine QSAR equation. Of the 24 QSAR equations model, the best QSAR equation was determined to determine the predictive value of MIC of quercetin derivatives compounds, i.e: MIC $=970.428+$ $(0.025$ Energy Total $)+(110.503$ Energy HOMO $)+(-100.354$ Energy LUMO $)+(-37.142 \log$ P) Of 91 compounds of quercetin derivative copounds tested, obtained 74 compounds with MIC values lower than quercetin and 2,6-diisopropyl quercetin was compound with the smallest predictive MIC value $(27.28 \mu \mathrm{g} / \mathrm{mL})$. The modification of the chemical structure of quercetin can increase the activity as a growth inhibitor of candida albicans
\end{abstract}

Keywords: quercetin, inhibitor, candida albicans, QSAR 


\section{Pendahuluan}

Candida albicans adalah sejenis jamur patogen bagi manusia yang terlibat dalam proses Oral Candidiasis (OC), hidup secara komensal di usus, faringeal oral, saluran kemih dan kulit [1]. Candida albicans merupakan spesies yang paling umum diisolasi dalam kasus klinis infeksi jamur invasive [2]. Patogenisitas Candida albicans dan kandidiasis lebih lanjut dapat terjadi dalam kondisi immunocompromised Di pasaran, obat kandidiasis sudah banyak beredar, salah satunya adalah nistatin. Selain nistatin, beberapa senyawa alam juga dapat mengobati kandidiasis, misalnya flavonoid sehingga flavonoid dapat digunakan sebagai struktur penuntun untuk dikembangkan menjadi obat kandidiasis baru.

Berdasarkan penelitian Seleem et al., 2016, dilaporkan ada 10 senyawa turunan flavonoid yang memiliki aktivitas sebagai penghambat pertumbuhan Candida albicans [3]. Kuersetin dan karvakrol adalah contoh dari senyawa flavonoid yang memiliki aktivitas sebagai penghambat pertumbuhan Candida albicans. Kuersetin memiliki nilai MIC sebesar $197 \mu \mathrm{g} / \mathrm{mL}$. Kuersetin adalah salah satu agen kemoprotektif yang menjanjikan terhadap efek dari kontaminan lingkungan pada hewan percobaan karena aktivitas biologis dan farmasi, yaitu: antioksidan, anti-inflamasi, antikarsinogenik dan antimikroba [4,5]. Mekanisme aksi kuersetin dalam inhibitor pertumbuhan Candida albicans adalah dengan cara merusak mannoprotein yang terdapat pada dinding sel Candida albican. Aktivitas kuersetin terhadap Candida albicans tersebut dipengaruhi oleh cincin aromatic yang memiliki gugus hidroksi pada struktur dasar kuersetin [6].

Penelitian ini bertujuan untuk mendesain senyawa turunan kuersetin agar memiliki aktivitas penghambatan pertumbuhan candida albicans yang lebih baik dengan metode analisis QSAR. QSAR (Quantitative StructureActivity Relationship) atau HKSA (Hubungan Kuantitatif Struktur Aktivitas) merupakan bagian penting dari proses rancang obat menggunakan kimia komputasi, dalam usaha mendapatkan suatu obat baru dengan aktivitas yang lebih besar, keselektifan yang lebih tinggi, toksisitas atau efek samping yang lebih rendah dan kenyamanan yang lebih besar. Selain itu dengan menggunakan model QSAR, akan lebih banyak menghemat biaya atau lebih ekonomis, karena untuk mendapatkan obat baru dengan aktivitas yang dikehendaki, faktor coba-coba ditekan sekecil mungkin sehingga jalur sintesis menjadi lebih pendek.

Pada penelitian ini struktur kuersetin dimodifikasi dengan mengganti atom $\mathrm{H}$ dengan beberapa gugus seperti alkoksi, alkil dan halogen. Persamaan QSAR dibentuk dengan analisis regresi multilinier, dengan penentuan deskriptor menggunakan hyperchem metode Semi Empiric Austin Model 1. Dengan penelitian ini diharapkan dapat diperoleh kandidat senyawa baru dengan potensi yang lebih besar dalam menghambat pertumbuhan candida albicans.

\section{Bahan dan Metode}

Bahan yang digunakan dalam penelitian ini antara lain : Struktur 2D/3D dari 10 senyawa golongan flavonoid sebagai inhibitor pertumbuhan candida albicans hasil penelitian Seleem et al, 2016 sebagai senyawa tranning set. Struktur 2D/3D senyawa modifikasi kuersetin sebanyak 91 senyawa sebagai senyawa uji.

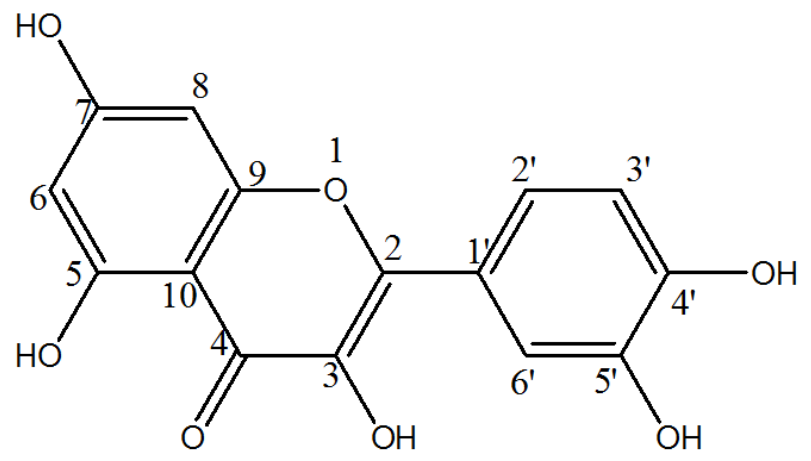

Gambar 1. Struktur kimia kuersetin 
Alat yang digunakan dalam penelitian ini antara lain : Perangkat Keras : Laptop A s u s X $450 \mathrm{C} \mathrm{C}$ Intel(R)Core(TM) i3-3217 CPU @1.80 GHz (4CPUs), 1.80 GHz, Intel(R) HD Graphics 4000, RAM 6GB, HDD 500GB. Perangkat lunak: Hyperchem 8.0.6, SPSS 16, Chemdraw ultra 10.0.

Metode penelitian yang digunakan mengacu pada metode standard analisis QSAR Semi Empiric Austin Model 1 yang pernah dilakukan Mumpuni et al, 2017 [7]. Penentuan deskriptor persamaan QSAR dengan cara menggambar struktur 3D senyawa tranning set dan senyawa turunan kuersetin menggunakan program Hyperchem 8.0.6. Optimasi geometri dilakukan dengan persamaan gradien sekawan (Conjugate gradient) algoritma Polak Ribiere dengan metode semiempirik AM 1 (batas konvergensi sebesar 0,001 kkal/A, batas iterasi sebesar 32767). Selanjutnya dilakukan perhitungan parameter elektronik dan molekular menggunakan QSAR properties. Penentuan persamaan QSAR dilakukan menggunakan metode analisis Multilinier dengan MIC sebagai variable tak bebas (terikat) dan parameter elektronik dan molekular sebagai variabel bebas. Selanjutnya parameter elektronik dan molecular dari senyawa uji diplot ke dalam persamaan QSAR terbaik hingga diperoleh nilai MIC prediksi.

\section{Hasil dan Pembahasan}

Analisis QSAR telah dilakukan dengan membuat model persamaan QSAR sebanyak 24 model persamaan dengan beberapa deskriptor yang memiliki korelasi kuat terhadap nilai MIC senyawa yaitu Energi LUMO, Energi HOMO, $\log \mathrm{P}$, muatan atom $\mathrm{C} 1$, muatan atom $\mathrm{C1}$ ', muatan atom $\mathrm{C} 3$ ' dan muatan atom C6'. Berdasarkan nilai $\mathrm{R}^{2}$, SE, F dan Sig. F, diperoleh 9 model persamaan regresi kuersetin yang memenuhi persyaratan. Nilai $\mathrm{R}^{2}$ digunakan untuk mengetahui persentase pengaruh variabel bebas yang berupa deskriptor-deskriptor $\left(\mathrm{x}_{1}, \mathrm{x}_{2}, \mathrm{x}_{3}, \ldots.\right)$ secara serentak berpengaruh terhadap variabel terikat yang berupa nilai MIC (y). Apabila nilai $\mathrm{R}^{2}=0$ berarti tidak ada pengaruh variabel-variabel bebas terhadap variabel terikat. Apabila nilai $\mathrm{R}^{2}=1$ berarti variabel bebas $100 \%$ mempengaruhi variabel terikat. Standard Error of the Estimate (SE) merupakan ukuran banyaknya kesalahan model regresi dalam memprediksi nilai variabel terikat (MIC). Model regresi dikatakan semakin baik dalam memprediksi nilai variabel terikat (MIC) apabila nilai SE lebih kecil daripada nilai standar deviasi (SD). Persamaan QSAR terbaik untuk senyawa turunan kuersetin adalah

MIC $=970.428+(0.025$ Energi Ikat $)+(110.503$ Energi HOMO $)+(-100.354$ Energi LUMO $)+(-37.142 \log \mathrm{P})$ $\mathrm{R}=0.938 \mathrm{R}^{2}=0.88, \mathrm{SE}=32.577$, Sig. $\mathrm{F}=0.016 \mathrm{Fhit} / \mathrm{Ftab}=1.769$

Gambar 2 menunjukkan plotting nilai MICprediksi Vs MICeksperimet setelah memasukkan nilai deskriptor senyawa tranning set ke dalam persamaaan QSAR terbaik. Dari grafik tersebut diperoleh nilai $\mathrm{R}^{2}=0.882$. Hal ini menunjukkan bahwa persamaan QSAR terpilih layak digunakan untuk penentuan nilai MICprediksi.

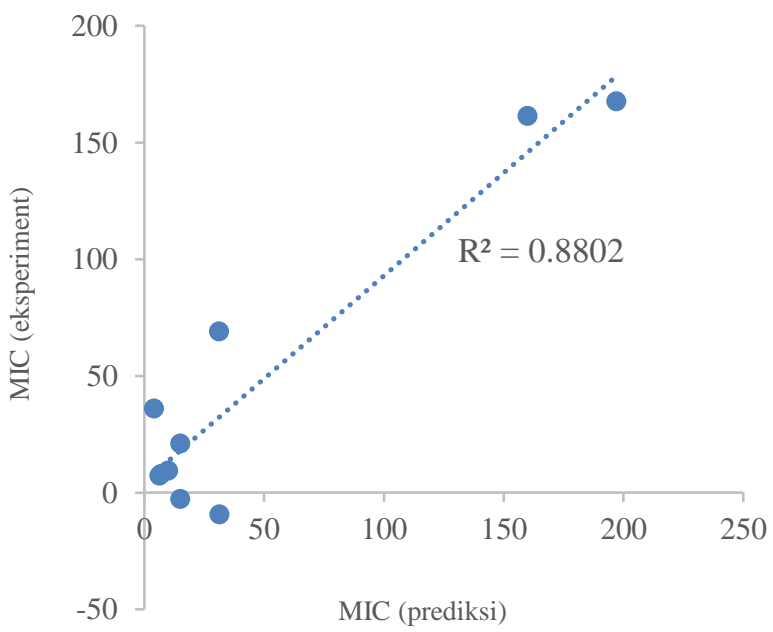


Gambar 2. Grafik plotting MICprediksi Vs MICeksperiment senyawa tranning set dengan model persamaan terbaik.

Variabel - variabel yang ada dalam persamaan QSAR terbaik antara lain energi ikat yang mempengaruhi kuat lemahnya ikatan antar atom dalam suatu senyawa, energi HOMO dan energi LUMO yang mempengaruhi daya ikat suatu senyawa dengan senyawa yang lainnya dan Log P yang menunjukkan polaritas dari suatu senyawa.

Perhitungan nilai MIC $_{\text {(prediksi) }}$ menunjukkan bahwa dari 91 senyawa uji diperoleh 74 senyawa turunan kuersetin yang memiliki nilai MIC lebih kecil dari kuersetin. Semakin kecil nilai MIC berarti aktivitas penghambatan semakin baik. Pada Tabel 1 ditunjukkan 10 senyawa turunan kuersetin dengan nilai MIC terendah. Dari tabel 1, dapat diketahui bahwa penggantian atom $\mathrm{H}$ dengan gugus alkil mampu meningkatkan nilai MIC dan 2',6- diisopropil kuersetin memiliki nilai MIC terkecil yaitu $27.28 \mu \mathrm{g} / \mathrm{mL}$. Gugus alkil (metil, etil, propil dan isopropil) dapat meningkatkan aktivitas penghambatan pertumbuhan Candida albicans dikarenakan gugus alkil merupakan pendorong elektron yang dapat membuat cincin benzene menjadi lebih reaktif dalam merusak mannoprotein dalam dinding sel candida albicans. Selain itu gugus alkil membuat kuersetin semakin bersifat non polar sehingga lebih mudah berinteraksi dengan dinding sel candida albicans yang terdiri dari karbohidrat, $\beta$-glukan, kitin dan mannan. Mannan atau sering disebut fosfomannoprotein atau kompleks fosfopeptidomannan [8]. Candida albicans sangat bergantung pada dinding selnya untuk berinteraksi dengan inangnya. Dinding sel Candida albicans berada di permukaan selnya sehingga membuat dinding sel menjadi struktur utama yang dimiliki untuk berinteraksi dengan inang. Ketika dinding sel candida albicans rusak, maka pertumbuhan menjadi terhambat.

Tabel 1. Nilai MIC (prediksi) 10 senyawa turunan kuersetin

\begin{tabular}{lll}
\hline No & Nama Senyawa & MIC $_{(\text {prediksi }}(\mu \mathrm{g} / \mathrm{mL})$ \\
\hline 1 & 2',6-diisopropil kuersetin & 27.28 \\
2 & 2',6-dipropil kuersetin & 28.58 \\
3 & $2^{2}, 5^{\prime}$-diisopropil kuersetin & 29.12 \\
4 & 2',5'-dipropil kuersetin & 30.67 \\
5 & 2',5',6-trietil kuersetin & 40.02 \\
6 & 2',5',6-triiodo kuersetin & 53.37 \\
7 & 5',6-dipropil kuersetin & 57.36 \\
8 & 5',6-diisopropil kuersetin & 62.63 \\
9 & 2',5'-diiodo kuersetin & 65.40 \\
10 & 2',6-diiodo kuersetin & 71.53 \\
\hline
\end{tabular}

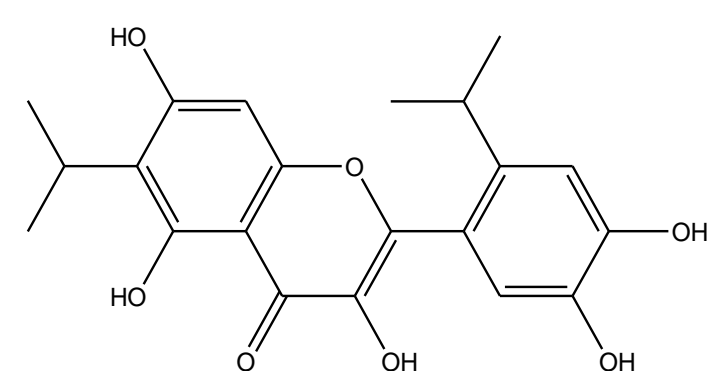

(A)

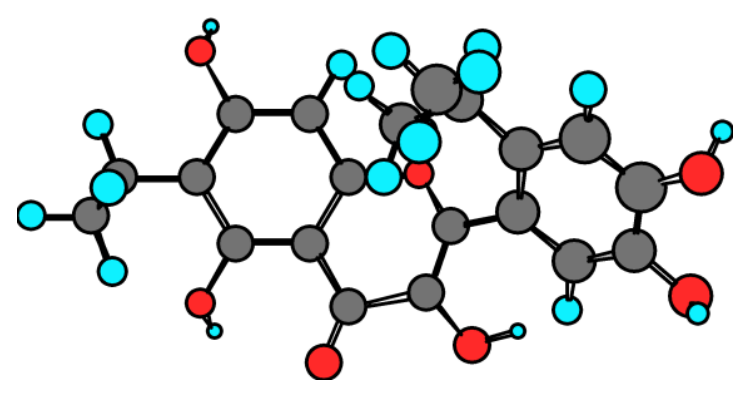

(B) 
Gambar 3. Struktur kimia 2',6- diisopropil kuersetin (A) 2D (B) 3D

\section{Kesimpulan}

Modifikasi struktur kimia senyawa kuersetin dapat meningkatkan aktivitasnya sebagai inhibitor pertumbuhan candida albicans

\section{Daftar Pustaka}

[1] Prieto D., Correia I., et al. (2016). Adaptation of Candida albicans to commensalism in the gut. Future Microbiol 11(4) Halaman : 567 - 583.

[2] Liu W., Li L. P., et al. (2014). Synergistic antifungal effect of glabridin and fluconazole. PLoS ONE 9 (7) e103442.

[3] Seleem D, Pardi V, et al. (2016). Review of flavonoids: A diverse group of natural compounds with anti-Candida albicans activity in vitro. j.archoralbio (76) Halaman: $76-83$.

[4] Cornard JP \& Merlin JC. (2002). Spectroscopic and structural study of complexes of quercetin with Al(III). J Inorg Biochem (92) Halaman 19-27.

[5] Murakami A, Ashida H, et al. (2008). Multitargeted cancer prevention by quercetin. Cancer Lett (269) Halaman 315-325

[6] Taechowisan T, Chanaphat S, et al. (2014). Antibacterial and Anticandidal Activities of New Flavonoids from Streptomyces sp . BT01; an endophyte in Boesenbergia rotunda (L.) Mansf. J Applied Pharm Sci. (4) Halaman 008 - 13.

[7] Mumpuni E, Mulatsari E,. (2017). QSAR Analysis on Apigenin Derivative Compounds as Antioxidant Using Semiempirical Austin Model 1. Asian J Chem (29) Halaman 1499 - 1505.

[8] Cannon RD, Chaffin WL,.(1999). Oral Colonization By Candida Albicans. Crit Rev Oral Biol Med. (10) Halaman : $359-383$. 